\title{
The impact of customer-specific marketing expenses on customer retention and customer profitability
}

\author{
Sander van Triest • Maurice J. G. Bun • \\ Erik M. van Raaij • Maarten J. A. Vernooij
}

Published online: 30 September 2008

(C) The Author(s) 2008. This article published with open access at Springerlink.com

\begin{abstract}
We study the effects of customer-specific marketing expenses on customer retention and customer profitability in a business-to-business setting. Using data from a company providing hygiene services, we look at the impact of a hitherto unstudied type of expense targeted at individual customer relationships: the offering of free equipment to customers. The data allow tracking the activities performed in more than 4,500 customer relationships over a period of 4 years. Retention rates are higher for customers targeted with free equipment, but this effect results from an interaction with customer size. First-order dynamic panel data analyses show that the impact of targeted marketing expenses on customer dollar profit is positive for large customers, but there is no effect for smaller customers. Thus, targeted marketing expenses seem to be a tool for relationship maintenance rather than customer development: they help in retaining large customers that generate more profit, but they do not seem to work in developing new customers into larger, more profitable ones.
\end{abstract}

Keywords Customer profitability $\cdot$ Customer-specific marketing expenses $\cdot$ Panel data

S. van Triest $(\square)$

Amsterdam Business School, University of Amsterdam,

Room E2.77, Roetersstraat 11, 1018 WB Amsterdam, The Netherlands

e-mail: s.p.vantriest@uva.nl

M. J. G. Bun

University of Amsterdam, Room E3.10, Roetersstraat 11, 1018 WB Amsterdam, The Netherlands e-mail: m.j.g.bun@uva.nl

E. M. van Raaij

Rotterdam School of Management, Erasmus University,

Room T10-40, Burg. Oudlaan 50, 3062 PA Rotterdam, The Netherlands

e-mail: eraaij@rsm.nl

M. J. A. Vernooij

Nyenrode Business University, Straatweg 25, 3621 BG Breukelen, The Netherlands

e-mail: m.vernooij@nyenrode.nl 
The traditional divide between marketing and finance is disappearing. Increasingly, marketing is made financially accountable, customer profitability has become a key marketing metric, and academic research on customer equity, customer (lifetime) value, and return on marketing is burgeoning (Blattberg and Deighton 1996; Rust et al. 2004b; Berger et al. 2006; Gupta et al. 2006). The financial analysis of marketing actions is shifting from the level of the customer segment to the level of the individual customer relationship. A core capability in a customer-level marketing strategy is to be able to target the right customer with the right marketing actions, such that the costs to serve a customer are in line with revenues from that customer, and profitability is enhanced (Kumar and Petersen 2005).

Previous studies have investigated the profitability impact of various marketing decisions, such as frequency and method of contacting customers, differential pricing of services, channel management, loyalty programs, and customer acquisition and retention spending (Reinartz and Kumar 2003; Campbell and Frei 2004; Thomas et al. 2004; Venkatesan and Kumar 2004; Kumar and Petersen 2005). With each additional empirical study into the profitability impact of marketing actions, our insight in the causal relationships between marketing decisions and firm performance is growing. The empirical base is slightly skewed towards financial services and catalog retailers. Where relationship-specific investments are studied, these expenses are on channel communications with individual customers, either direct mail catalogs (Gonul and Shi 1998; Reinartz and Kumar 2000, 2003) or a multichannel mix including meetings, telephone contacts, web-based contacts, and direct mail (Venkatesan and Kumar 2004; Reinartz et al. 2005). We add to the extant literature with an analysis of a rather different type of customer-specific marketing expenses: the provision of free equipment to business customers. Our sample firm selectively targets customers with equipment at substantial costs: for the targeted customers (some 25\% receive equipment), equipment costs average $20 \%$ of their sales. We do not model customer lifetime value or try to predict the future profitability of individual customers. In this paper, we analyze actual data on revenues, product costs, and investments in relationship-specific assets related to individual customers, and assess the impact of marketing investments on customer retention and customer profitability.

Previous work related to this type of marketing investment in relationship-specific assets is either of a conceptual nature (Ghosh and John 1999) or empirically studies its links with opportunism and commitment (Brown et al. 2000; Jap and Ganesan 2000; Rokkan et al. 2003). In this paper, we apply survival analysis to empirically analyze the impacts of such investments on retention and panel data analysis to analyze its impact on profitability. These analyses extend the current insights in "return-on-marketing" (Rust et al. 2004b) beyond marketing communications and will help provide managers with a better understanding of when to use this type of relationship-specific marketing investment.

The customer-specific marketing expenses we study in this paper are used as a customer relationship management tool. At the discretion of marketing management, some customers are provided with free equipment under the assumption that this will strengthen the customer relationship and improve firm profitability (Brown et al. 2000). The key question is whether these relationship-specific expenses actually create value for the supplier (Srivastava et al. 1998; Rust et al. 2004a). In other 
words, are the relationship-specific expenses "money well spent"? To analyze this, data are required on the profitability of individual customer relationships over a number of years, as well as on the marketing expenses targeted at customers. We have customer profitability data from one firm in a business-to-business setting, that allows us to track revenues, cost of goods sold, service costs, and targeted marketing expenses for more than 4,500 customer relationships over 4 years. The firm provides hygiene services to business customers, with the main focus on supplying detergent liquids, soap, and other cleaning chemicals. Next to this, it offers technical support and advice on hygiene issues, and it invests in customer relationships by placing free equipment (such as detergent dosing systems) at customer sites. We identify the provision of free equipment as the targeted marketing activity. The level of technical support is induced by operational characteristics (e.g., in case of break-downs) rather than being a choice made by the supplier. As such, there is no trade-off between equipment and technical service as two competing types of marketing expenses (Naik and Raman 2003). We track the impact of these targeted expenses on customer retention and customer profitability for thousands of individual customer relationships. We find that retention rates are higher for targeted customers, but this effect results from an interaction with customer size. Panel data analyses show that the impact on customer dollar profit is positive only for large customers. Thus, targeted marketing expenses seem to be a tool for relationship maintenance rather than customer development: they help in retaining large customers that generate more profit, but they do not seem to work in developing new customers into larger, more profitable ones.

The paper is structured as follows: In the next section, we define customerspecific marketing expenses, and we draw up the research questions. Then, we present background information on our database, followed by the empirical analyses. We conclude with recommendations and limitations.

\section{Customer-specific marketing expenses}

Consistent with Webster (1992), we define marketing expenses as all costs made to start and maintain a customer relationship. We limit these expenses to those for which the company does not directly receive a compensation. Marketing expenses therefore include the "standard" categories, such as market research, sales force, and advertising, but they also include acquisition costs such as free products, discounts and cash-backs, the costs of loyalty programs (e.g., frequent flyer miles), and the costs of freely available service and support (e.g., toll-free help desks). Marketing expenses do not include product and delivery costs or services that are offered at a market price, for example, service support that is charged at full cost to the customer. The aim of marketing expenses is to generate returns in terms of customer attraction (producing cash flows from new customers), customer retention (increasing the length of the customer lifetime), and/or customer development (increasing cash flows from existing customers) (Rust et al. 2004b; Kamakura et al. 2005).

Within the category of marketing expenses, we can make a distinction between general marketing expenses and customer-specific marketing expenses. Expenses of the first type are part of the value proposition to all customers. Not all customers will 
make use of this offer, and for those customers that do request such a service, sales revenue or profitability is not necessarily expected to increase. For example, a customer dialing a toll-free help line that is part of his/her Internet subscription will probably not take up more subscriptions, and a customer requiring support from service mechanics to repair faulty equipment will not buy more equipment on the spot. Just like advertising and sponsoring, however, providing these services can improve the perceived quality of the company and its offerings. These expenses are aimed at increasing overall profitability, while accepting that the costs are not necessarily recovered from the specific customers that cause the costs.

Customer-specific marketing expenses, on the other hand, are made with the aim to increase the profitability of these specifically targeted customers. Examples of such expenses are special events organized for selected customers and the placement of assets paid for by the seller at the customer's site. Ice cream maker HB, for instance, has offered freezers free of charge to retail outlets that sell ice cream (McDowell 1996). Expenses incurred for such selected relationships need to be recovered from that specific customer relationship. The return of these expenses should come from increased retention and/or development of existing customers. In other words, this kind of marketing activity targeted at specific customer relationships should lead to reduced customer defection and/or increased customer spending, either as a result of buying more products, or as a result of buying higher-margin products (Bolton et al. 2004).

In line with the theoretical framework of Bolton et al. (2004) of customer asset management, the underlying rationale is that customer-specific marketing expenses (as one type of marketing instrument) influence customer perceptions of the relationship. These supplier-made investments in the relationship may increase customer-perceived switching costs, defined as the perceived economic and psychological costs associated with changing from one alternative to another (Jones et al. 2002). Customer-specific marketing expenses could affect all three core customer perceptions driving customer behavior as identified by Bolton et al. (2004): price perceptions, commitment, and satisfaction. To the best of our knowledge, there have not been any empirical studies into the performance effects of this specific type of marketing instrument. Thus, we will study two questions in this paper:

1. What is the impact of customer-specific marketing expenses on customer retention?

2. What is the impact of customer-specific marketing expenses on customer profitability?

\section{Data}

We have access to revenue, cost, and marketing expense data for more than 4,500 customers of a company active in the hygiene industry. The company develops, markets, and services its products, which are mainly detergents, soap, and other cleaning chemicals. It serves industrial customers, either directly or through wholesalers. It is a business unit of a large diversified firm, and the production facilities are separate cost centers within the diversified firm. It pays standard 
transfer prices to its production facilities. As a consequence, the actual production costs are not relevant with respect to the current research project. The products are used in a variety of settings, for example, in the kitchens of restaurants, by commercial contract cleaners, and in the process installations of breweries. Depending on the application, customers receive extra advice on how to organize their hygiene and get support from service mechanics, and are sometimes offered free equipment to be used in conjunction with the hygiene products.

The company initiated a customer profitability project to provide more insight into costs and revenues, and help in improving the results. The added insights proved valuable and prompted the company to implement customer profitability analysis (CPA) in day-to-day management. The data underlying this study covers the first 4 years of CPA data. We include the following variables in our analyses:

(a) Revenues: the net revenue (after discounts, rebates, and bonuses) per customer.

(b) Product costs: the products bought by the customer are recorded at intracompany transfer prices. As explained above, product costs cannot be influenced by the company. Product costs have no customer-specific components (no customized products).

(c) Equipment: Selected customers receive equipment free of charge. Low-cost equipment is recorded as an expense; more expensive equipment is recorded as an asset and subsequently depreciated. Relevant costs are known for each customer.

(d) Service: Service mechanics record the time of all visits they make to customers, and the costs of the service department are allocated based on this time.

The customer profitability numbers that result from this model are quite unique in the sense that they cover a substantial part of customer-specific costs. For example, knowing the product costs per customer allows the calculation of individual gross margins. In this respect, the model extends recent work by Reinartz and Kumar (2000, 2003) and Venkatesan and Kumar (2004), who use average gross margins in performing customer profitability analyses.

\section{Empirical results}

\subsection{Descriptives}

We have data on 4,721 different customers. Not all customers are active in every year. Panel A of Table 1 shows the number of active customers in each of the 4 years of our study and what proportion of active customers incurred service or equipment costs. We see that the number of customers declines, but the proportion of active customers who incur service and/or equipment costs increases over the 4 years. On average, some $30 \%$ of customers are visited by service representatives, and some $25 \%$ of customers are targeted with free equipment.

Panel B presents the average of each item in the customer profitability model. On average, product costs represent some $30 \%$ of customer sales, that is, gross margins on sales are approximately $70 \%$. Average service and equipment costs are $7 \%$ and $3 \%$ of sales, respectively, but since only a minority of customers incurs these costs, 
Table 1 Descriptive statistics

\begin{tabular}{lrrrr}
\hline & Year 1 & Year 2 & Year 3 & Year 4 \\
\hline Panel A & & & & \\
Number of active customers & 3,112 & 3,067 & 2,665 & 2,474 \\
Proportion receiving service & $29.2 \%$ & $31.6 \%$ & $30.6 \%$ & $34.1 \%$ \\
Proportion receiving equipment & $19.0 \%$ & $24.8 \%$ & $24.6 \%$ & $27.2 \%$ \\
Panel B & & & & \\
Product costs & 33.2 & 34.7 & 34.0 & 31.1 \\
Service costs & 7.4 & 6.4 & 3.0 & 8.5 \\
Equipment costs & 3.2 & 3.7 & 58.6 & 5.3 \\
Customer profitability & 56.2 & 55.1 & & 55.1 \\
\hline
\end{tabular}

the median values of both are zero. The average customer profitability after deduction of product costs, service costs, and equipment costs is approximately $56 \%$, while the (untabulated) median customer profitability is about $64 \%$.

Due to the nature of our data, we perform our analysis of the impact of targeted marketing expenses on customer retention and customer profitability separately. The typical approach would be to consider a vector autoregressive specification modeling retention and profitability jointly, but our observations span four periods only. Although we do have detailed customer profitability numbers for all 4 years, because of the limited number of periods, we model retention as a discrete variable rather than a continuous duration variable (cf. Reinartz et al. 2005). Hence, regarding retention, the available panel is necessarily unbalanced and, therefore, different from the balanced profitability panel. Once the customer defects, we have no data available anymore.

\subsection{The impact of targeted marketing expenses on customer retention}

In Table 2, we compare, for each year, the retention rates of customers who receive equipment in that year with those who do not. For example, in year 1, 590 of 3,112 customers received equipment; of these 590 customers, 502 recorded sales in year 2 . We see that $75 \%$ of all year-1 customers are still active in year 2 , but that the retention rate differs significantly between the two segments: whereas $85 \%$ of customers receiving equipment in year 1 record sales in year 2 , only $73 \%$ of nontargeted customers do so. For years 2 and 3, the pattern is the same, with customers receiving equipment showing significantly higher retention rates.

The univariate analysis of Table 2 suggests that targeted activities lead to higher retention. However, untabulated results show a substantial correlation between

Table 2 Year-to-year retention rate of targeted vs nontargeted customers

\begin{tabular}{lrrrrrrrrr}
\hline Equipment & Year 1 & Year 2 & Percent & Year 2 & Year 3 & Percent & Year 3 & Year 4 & Percent \\
\hline Yes & 590 & 502 & 85.1 & 724 & 571 & 78.9 & 653 & 524 & 80.2 \\
No & 2,522 & 1,837 & 72.8 & 2,343 & 1,592 & 67.9 & 2,012 & 1,356 & 67.4 \\
& 3,112 & 2,339 & 75.2 & 3,067 & 2,163 & 70.5 & 2,665 & 1,880 & 70.5 \\
\hline
\end{tabular}

All retention rates differ significantly between the two segments at the $1 \%$ level according to a chi-square test 
Table 3 Logistic regression on the event of retention

\begin{tabular}{lcr}
\hline & Direct effects & Interaction \\
\hline Constant & $-6.66(0.21)$ & $-6.12(0.22)$ \\
Log sales & $1.07(0.03)$ & $0.99(0.03)$ \\
Targeted & $-0.10(0.07)$ & $-3.21(0.61)$ \\
Log sales $\times$ targeted & & $0.44(0.09)$ \\
McFadden $R^{2}$ & 0.203 & 0.206 \\
\hline
\end{tabular}

Standard errors in parentheses

customer size, targeting, and retention. To analyze the retention and defection rates of the customers, we apply survival analysis: we are interested in the question of whether a customer will defect in a period. This type of analysis is often performed using a Cox proportional hazard model (e.g., Kalbfleisch and Prentice 1980). However, because of the very limited number of periods (effectively three because of right-censoring), applying a regular hazard analysis is not appropriate. Therefore, we use a discrete time survival model (Singer and Willett 1991; HassabElnaby et al. 2005). We estimate the following specification:

$$
\begin{gathered}
\operatorname{Retain}_{i, t+1}^{*}=\beta_{0}+\beta_{1} \operatorname{LnSales}_{i t}+\beta_{2} \text { DTarget }_{i t}+\varepsilon_{i t} \\
\operatorname{Retain}_{i, t+1}=1 \text { if } \operatorname{Retain}_{i, t+1}^{*}>0 \\
\operatorname{Retain}_{i, t+1}=0 \text { if } \operatorname{Retain}_{i, t+1}^{*} \leq 0
\end{gathered}
$$

with

$\operatorname{Retain}_{i, t+1}$ dummy variable that takes on 1 if customer $i$ records sales in year $t+1$ (so it is retained), and 0 otherwise

LnSales $_{i t} \quad \log$ of sales revenue of customer $i$ in year $t$

DTarget $_{i t}$ dummy variable that takes on 1 if customer $i$ is provided with free equipment in year $t$, and 0 otherwise

Since we have 4 years of data, the information of year 4 can only be used to determine the dependent variable, Retain $n_{i, t+1}$. We have 8,844 observations on whether customers are retained. The equation is estimated with direct effects, and with an interaction term to account for customer heterogeneity, using maximum likelihood and

Table 4 Logistic regression on the event of retention

\begin{tabular}{lcccc}
\hline & Small (S1) & S2 & S3 & Large (S4) \\
\hline Constant & $-7.59(1.13)$ & $-5.96(1.23)$ & $-6.41(1.29)$ & $-2.68(1.63)$ \\
Log sales & $1.23(0.19)$ & $0.99(0.18)$ & $1.03(0.17)$ & $0.61(0.18)$ \\
Targeted & $-0.52(0.15)$ & $-0.28(0.12)$ & $0.23(0.15)$ & $1.18(0.33)$ \\
McFadden $R^{2}$ & 0.017 & 0.012 & 0.022 & 0.058 \\
\hline
\end{tabular}

Standard errors in parentheses 
assuming a logistic distribution for the disturbances. In Tables 3 and 4, we present the results for this logit model.

In Table 3, we see that larger customers are less likely to defect. This result is consistent over both models. There is no direct effect of targeted marketing activities in a simple specification involving only customer size and targeted activities. Including an interaction term with customer size leads to a direct effect of targeted activities on retention that is negative, but the interaction term is positive. In Table 4, we control for customer heterogeneity by partitioning the sample into four equal segments of 2,211 customers, based on customer sales revenues at the time of observation. In all analyses, the coefficient on customer size is significant and positive, while the coefficient on targeted activities goes from significantly negative for the smallest customers to significantly positive for the largest. The low McFadden $R^{2}$ values for the partitioned regressions show that customer size is the main influence on retention. Thus, marketing activities do not achieve retention as such, but work only for the largest customers. The apparent relation between targeted activities and retention of Table 2 results mainly from the correlation of targeting with customer size.

The significantly negative coefficient for the smallest customer segment is surprising. Discussion with company management did not lead to clear explanations. It is possible that smaller customers, who are on the verge of leaving, voice their dissatisfaction loudly, to which the company reacts with targeted activities that arrive too late. Also, it may be opportunistic behavior of small customers who are already thinking of switching suppliers, and try to profit from the relationship in this final period.

\subsection{The impact on customer profitability}

Next, we study the impact of targeted marketing activities on customer dollar profitability, which we calculate as customer revenue minus direct customer costs (consisting of product, equipment, and service costs). As a first indicator, we compare two groups of customers over 4 years: targeted customers who receive equipment every year $(N=320)$ and customers who record sales every year but never receive equipment (nontargeted, $N=939$ ). Table 5 shows substantial differences

Table 5 Characteristics of targeted vs nontargeted customers

\begin{tabular}{|c|c|c|c|c|c|c|c|c|}
\hline & \multicolumn{2}{|l|}{ Year 1} & \multicolumn{2}{|l|}{ Year 2} & \multicolumn{2}{|l|}{ Year 3} & \multicolumn{2}{|l|}{ Year 4} \\
\hline & Mean & Median & Mean & Median & Mean & Median & Mean & Median \\
\hline \multicolumn{9}{|l|}{ Targeted } \\
\hline Sales & $4,720.4$ & 670.7 & $4,910.6$ & 711.5 & $5,200.3$ & 614.8 & $5,357.7$ & 634.4 \\
\hline Dollar profit & $2,504.6$ & 272.6 & $2,425.1$ & 262.6 & $2,534.2$ & 256.8 & $2,385.7$ & 186.5 \\
\hline Profitability \% & 29.6 & 45.0 & 34.3 & 45.3 & 40.9 & 49.7 & 26.3 & 40.7 \\
\hline \multicolumn{9}{|l|}{ Nontargeted } \\
\hline Sales & 662.1 & 158.8 & 654.8 & 172.1 & 714.7 & 163.7 & 683.1 & 147.7 \\
\hline Dollar profit & 411.6 & 99.0 & 394.0 & 107.9 & 437.1 & 105.7 & 420.4 & 101.5 \\
\hline Profitability \% & 64.4 & 67.2 & 62.6 & 65.5 & 64.8 & 66.3 & 67.8 & 70.7 \\
\hline
\end{tabular}

All values are significantly different between the two groups at the $1 \%$ level using a Mann-Whitney test 
between these two groups: customers that always receive equipment are much larger and have much higher profits, although they do have a lower profitability margin (profit as a percentage of sales).

To evaluate the impact of targeted marketing activities, we employ a panel data analysis. We use a balanced panel, i.e., we select customers that record sales in all 4 years. This yields a total of 1,562 customers; hence, the dimensions of the panel data are $T=4$ and $N=1,562$. We estimate the following empirical model for customer profitability:

$$
\text { Profit }_{i t}=\gamma \text { Profit }_{i, t-1}+\beta \text { DTarget }_{i t}+\eta_{i}+\lambda_{t}+\varepsilon_{i t}
$$

where Profit ${ }_{i t}$ is the customer profitability, and DTarget ${ }_{i t}$ is the dummy variable as used in the survival Eq. 1. Furthermore, to control for unobserved customer-specific factors, we include customer-specific effects $\eta_{i}$, while time effects $\lambda_{t}$ model any relevant factors common to all customers. Finally, we assume the idiosyncratic error term $\varepsilon_{i t}$ to be uncorrelated over time and across customers, but we allow for general heteroskedasticity patterns.

Among other things, the model above relates current customer profitability to profitability in the previous year. It can be rewritten in a form more easy to interpret, i.e.,

$$
\Delta \text { Profit }_{i t}=-(1-\gamma)\left(\text { Profit }_{i, t-1}-\alpha_{i}\right)+\beta \text { DTarget }_{i t}+\lambda_{t}+\varepsilon_{i t}
$$

with $\alpha_{i}=\eta_{i} /(1-\gamma)$. Equation 3 implies that the change in customer profitability is determined by an adjustment of profitability towards a "natural" or "equilibrium" level $\alpha_{i}$, which may be different across customers, e.g., due to customer size. The speed of adjustment of customer profitability towards the natural level is equal to $(1-\gamma)$. It is to be expected that there is partial adjustment, i.e., $0<\gamma<1$. The effect of targeted marketing activities is measured by $\beta$. Should targeted marketing activities help in developing customer profitability, we would expect a positive sign on this coefficient.

An important issue in evaluating the effectiveness of targeting marketing activities is the presence of selection bias. In other words, assignment of marketing activities to customers is not random and may be correlated, among other things, with customer profitability itself. The usual way to deal with this endogeneity problem in crosssection analysis is to implement either a control function approach (Heckman 1978) or implement some instrumental variables method to take into account the endogeneity of the targeted dummy variable. The main problem with these methods, however, is that they require valid instruments. A key assumption for a valid instrument is that it is only related to the outcome variable of interest (in our case, customer profitability) via the targeted marketing dummy. In our data, we do not have such instruments available; hence, we have to refrain from using such methods.

Instead, our profitability model (Eq. 2) is closely related to the differences-indifferences methodology (Ashenfelter and Card 1985) used widely in the program evaluation literature. We exploit the availability of panel data for a subset of customers to take into account in our empirical model of profitability both selection upon observables (lagged profitability) and unobservables (customer specific effect). As such, the model is more general than the traditional differences-in-differences approach based on only two time periods where selection is based on either the permanent component of the outcome variable (i.e., customer specific effect) or values 
of the outcome variable prior to treatment (i.e., lagged profitability). Given that we have more than two periods available, we can control for both types of selection rules.

We present estimation results of model Eq. 3 using both the level of customer profitability $(N=1,562)$ and the logarithm of profitability. In the latter case, a slightly smaller sample is available $(N=1,367)$ because, for some customers, losses have been reported. In a standard differences-in-differences approach, least squares is a consistent estimator (Ashenfelter and Card 1985) whether selection has been based on either a customer specific effect or on lagged profitability. However, as we control simultaneously for both types of selection, the resulting empirical specification is a linear dynamic panel data model. To obtain consistent estimates of the unknown parameters of model Eq. 3 the use of efficient generalized method of moments (GMM) is warranted (Arellano and Bond 1991). It is well known that the least squares estimator is biased and inconsistent (for finite $T$ and large $N$ ) in fixed effects panel data models with predetermined or endogenous regressors. A prominent example is a model with autoregressive dynamics (Nickell 1981), such as the empirical specification above. Moreover, although we explicitly control for various types of selection rules regarding the targeted activities dummy, it is still likely that there is a lagged feedback mechanism from the time variant unobserved component of profitability resulting in a lack of exogeneity of this regressor too.

We present estimation results of the specification above using the system GMM estimator proposed by Blundell and Bond (1998), run on the Ox version of DPD (Doornik et al. 2006). Regarding the lagged dependent variable regressor, we exploit all available moment conditions arising from the model assumptions. Regarding the targeted activities dummy, we do not rule out the possibility of lagged feedback from profitability to targeted marketing activities (see the Appendix for more details). The various coefficient estimates and their estimated standard deviations are presented in Table 6. Panel A presents the results using the level of customer profitability, Panel $\mathrm{B}$ using the natural logarithm of customer profitability. Also reported are $p$ values of the Sargan test of overidentifying restrictions (Sargan 1958; Hansen 1982), which tests the validity of both specification and moment conditions.

Table 6 GMM estimation results for Eq. 2

\begin{tabular}{llcr}
\hline & $\gamma$ & $\beta$ & Sargan \\
\hline Panel A & & & \\
Full sample & $0.78(0.17)$ & $2,078(1,064)$ & 0.10 \\
1st quartile & $0.52(0.11)$ & $67(128)$ & 0.68 \\
2nd quartile & $0.27(0.14)$ & $31(119)$ & 0.35 \\
3rd quartile & $0.75(0.20)$ & $-360(217)$ & 0.00 \\
4th quartile & $0.71(0.22)$ & $5,925(3,775)$ & 0.36 \\
Panel B & & & $0.61(0.09)$ \\
Full sample & $0.40(0.06)$ & $-0.07(0.14)$ & 0.00 \\
1st quartile & $0.33(0.07)$ & $0.12(0.08)$ & 0.02 \\
2nd quartile & $0.42(0.09)$ & $0.08(0.06)$ & 0.05 \\
3rd quartile & $0.55(0.07)$ & $0.11(0.06)$ & 0.71 \\
4th quartile & $0.86(0.06)$ & & \\
\hline
\end{tabular}

Standard errors in parentheses 
We present full-sample results, as well as estimates from customer size-based subsamples. The estimates in general show that there is positive persistence over time in customer profitability as measured by $\gamma$. Regarding $\beta$, for the full sample, targeted marketing activities have a significant positive impact. However, the Sargan $p$ values for the full sample are low, indicating a potential specification problem especially for the logarithmic model. Although the Sargan test does not provide information on how to improve the model specification, one obvious cause could be parameter heterogeneity. It is natural to expect that both profitability persistence and the impact of targeted activities depend on customer size. Hence, we split the full sample into subsamples to verify empirically this conjecture of parameter heterogeneity. The subsamples are constructed according to the quartiles of the sales distribution in the first year. In such a way, we allow for parameter heterogeneity depending on customer size as measured by their sales revenues. When we contrast the smallest customers (first quartile) with the largest, we observe that the $\beta$ coefficient is small or negative, yet nonsignificant for the smallest customers, while this coefficient is positive but only marginally significant for the largest customers. Sargan $p$ values indicate no serious specification problems for the subsamples of smallest and largest customers. Just as with the retention analysis, a substantial size effect seems present. Persistence seems to increase with customer size, indicating a slower speed of adjustment for larger customers. We experimented with various alternative specifications, e.g., using a finer grid to construct subsamples or trimming the data to dismiss extreme observations. The (unreported) results from these robustness checks show a similar pattern for the coefficient estimates as in Table 6. In all, the results suggest that targeted marketing activities do not really help in developing the profitability of customers. Since targeted customers are substantially more profitable in dollar terms (see Table 5), this points to interpreting these activities as relationship maintenance tools.

\section{Conclusions}

This article examines the impact of targeted marketing expenses on customer retention and customer profitability. We analyze customer-level data on sales, marketing, and service activities for a large number of customer relationships over a period of 4 years in a business-to-business setting. We find that customers who are targeted with customer-specific relationship expenses show higher retention rates, and that these customers have higher sales and higher profits. However, survival and panel data analyses suggest that the targeted marketing expenses are not directly resulting in these higher retention and profitability rates. Customers receiving free equipment are generally larger and have higher dollar profits (even while they show lower profitability margins). Survival analysis shows customer retention is related to customer size, rather than to targeted marketing activities as such. Our panel analyses show that the use of targeted marketing activities does not seem to help in developing customers with respect to profitability. In our case company, targeted marketing activities are much more a tool for managing and maintaining relationships with large customers than for generating extra returns. 
Our analysis supports the idea that this kind of relationship-specific investment works as a token of commitment from the supplier to the customer (cf. Gounaris 2005). According to Rokkan et al. (2003), such an investment can lead to a bonding effect between supplier and customer, strengthening the relationship and leading the customer to refrain from opportunistic behavior, provided that the relationship is characterized by a strong norm of solidarity. In the absence of such a strong norm of solidarity, targeted investments may lead to an expropriation effect: opportunistic expropriation of value on the part of the receiver (in our case, the customer). A possible indication of such opportunistic behavior is the negative effect of targeted activities on customer retention for the smallest customers, as is the fact that customers who receive free equipment have significantly lower profitability margins than customers who do not receive free equipment.

Acknowledgment We thank Peeter Verlegh, as well as participants at meetings in Gothenburg, Rotterdam, and Amsterdam, for helpful comments.

Open Access This article is distributed under the terms of the Creative Commons Attribution Noncommercial License which permits any noncommercial use, distribution, and reproduction in any medium, provided the original author(s) and source are credited.

\section{Appendix}

This appendix serves to give estimation details for the regression analysis as performed in section 3.3 of the paper. We estimate the following empirical model for customer profitability:

$$
\text { Profit }_{i t}=\gamma \text { Profit }_{i, t-1}+\beta \text { DTarget }_{i t}+\eta_{i}+\lambda_{t}+\varepsilon_{i t}
$$

Efficient GMM estimation has been performed to get consistent estimates of the unknown parameters. We report two-step GMM estimates using a consistent preliminary estimate of the covariance matrix of the moment conditions.

Regarding the lagged dependent variable regressor, we exploit all available moment conditions arising from the model assumptions. Following Arellano and Bond (1991), the levels equation has been first-differenced to eliminate customerspecific effects. Like the within transformation, first differencing gets rid of the timeinvariant, customer-specific effects. However, it does not solve the endogeneity problem because the transformed lagged dependent variable regressor $\Delta$ Profit $_{i, t-1}$ will still be correlated with the transformed error $\Delta \varepsilon_{i t}$. Provided that the original disturbances $\varepsilon_{i t}$ are not autocorrelated over time, moment conditions involving lagged values of the dependent variable can be used. More in particular, regarding the autoregressive part of the model, we use

$$
E\left[\operatorname{Profit}_{i, t-s} \Delta \varepsilon_{i t}\right]=0(t=2, \ldots, \quad T ; \quad s=2, \ldots, t)
$$

The resulting set of moment conditions has been combined with moment conditions from the levels equation (Blundell and Bond 1998), which arise from a mean stationarity assumption on the initial observations. This assumption implies that $\Delta$ Profit $_{i, t-1}$ is uncorrelated with the firm-specific effect in the original levels 
equation; hence, lagged values of the first differenced dependent variable can be used as instruments too. Specifically, following Blundell and Bond (1998), we use

$$
E\left[\varepsilon_{i t} \Delta \text { Profit }_{i, t-1}\right]=0(t=2, \ldots, \quad T) .
$$

Summarizing, in total, we exploit $T(T-1) / 2+T-1$ moment conditions originating from the autoregressive part of the model.

Depending on the nature of the targeted activities dummy, more moment conditions are available. We do not rule out the possibility of lagged feedback from profitability to targeted marketing activities. In other words, we consider DTarget ${ }_{i t}$ as an endogenous variable too. Regarding the model in first differences, this leads to the moment conditions

$$
E\left[\text { DTarget }_{i, t-s} \Delta \varepsilon_{i t}\right]=0(t=2, \ldots, T ; s=1, \ldots, t) .
$$

In addition, assuming also that $\Delta$ DTarget $_{i t}$ is uncorrelated with the firm-specific effects, we have the additional moment conditions from the levels equation

$$
E\left[\varepsilon_{i t} \Delta \text { DTarget }_{i t}\right]=0(t=2, \ldots, \quad T) .
$$

\section{References}

Arellano, M., \& Bond, S. (1991). Some tests of specification for panel data: Monte Carlo evidence and an application to employment equations. The Review of Economic Studies, 58, 277-297. doi:10.2307/ 2297968

Ashenfelter, O., \& Card, D. (1985). Using the longitudinal structure of earnings to estimate the effect of training programs. The Review of Economics and Statistics, 67(4), 648-660. doi:10.2307/1924810.

Berger, P. D., Eechambadi, N., George, M., Lehmann, D. R., Rizley, R., \& Venkatesan, R. (2006). From customer lifetime value to shareholder value: theory, empirical evidence, and issues for future research. Journal of Service Research, 9(2), 156-167. doi:10.1177/1094670506293569.

Blattberg, R. C., \& Deighton, J. (1996). Manage marketing by the customer equity test. Harvard Business Review, 74(4), 136-144. July-August.

Blundell, R., \& Bond, S. (1998). Initial conditions and moment restrictions in dynamic panel data models. Journal of Econometrics, 87(1), 115-143. doi:10.1016/S0304-4076(98)00009-8.

Bolton, R. N., Lemon, K. N., \& Verhoef, P. C. (2004). The theoretical underpinnings of customer asset management: a framework and propositions for future research. Journal of the Academy of Marketing Science, 32(3), 271-292. doi:10.1177/0092070304263341.

Brown, J. R., Dev, C. S., \& Lee, D.-J. (2000). Managing marketing channel opportunism: the efficacy of alternative governance mechanisms. Journal of Marketing, 64(2), 51-65. doi:10.1509/ jmkg.64.2.51.17995.

Campbell, D., \& Frei, F. (2004). The persistence of customer profitability: empirical evidence and implications from a financial services firm. Journal of Service Research, 7(2), 107-123. doi:10.1177/ 1094670504268419.

Doornik, J. A., Arellano, M., \& Bond, S. (2006). Panel data estimation using DPD for Ox. www.doornik. com/download.html.

Ghosh, M., \& John, G. (1999). Governance value analysis and marketing strategy. Journal of Marketing, 63(special issue), 131-145. doi:10.2307/1252107.

Gonul, F., \& Shi, M. Z. (1998). Optimal mailing of catalogs: a new methodology using estimable structural dynamic programming models. Management Science, 44(9), 1249-1262.

Gounaris, S. P. (2005). Trust and commitment influences on customer retention: insights from businessto-business services. Journal of Business Research, 58(2), 126-140. doi:10.1016/S0148-2963(03) 00122-X. 
Gupta, S., Hanssens, D., Hardie, B., Kahn, W., Kumar, V., Lin, N., et al. (2006). Modeling customer lifetime value. Journal of Service Research, 9(2), 139-155. doi:10.1177/1094670506293810.

Hansen, L. P. (1982). Large sample properties of generalized method of moments estimators. Econometrica, 50(3), 1029-1054. doi:10.2307/1912775.

HassabElnaby, H. R., Said, A. A., \& Wier, B. (2005). The retention of nonfinancial performance measures in compensation contracts. Journal of Management Accounting Research, 17, 23-42. doi:10.2308/ jmar.2005.17.1.23.

Heckman, J. J. (1978). Dummy endogenous variables in a simultaneous equation system. Econometrica, 46(4), 931-959. doi:10.2307/1909757.

Jap, S. D., \& Ganesan, S. (2000). Control mechanisms and the relationship life cycle: implications for safeguarding specific investments and developing commitment. JMR, Journal of Marketing Research, 37(2), 227-245. doi:10.1509/jmkr.37.2.227.18735.

Jones, M. A., Mothersbaugh, D. L., \& Beatty, S. E. (2002). Why customers stay: measuring the underlying dimensions of services switching costs and managing their differential strategic outcomes. Journal of Business Research, 55(6), 441-450. doi:10.1016/S0148-2963(00)00168-5.

Kalbfleisch, J. D., \& Prentice, R. L. (1980). The statistical analysis of failure time data. New York: Wiley.

Kamakura, W., Mela, C. F., Ansari, A., Bodapati, A., Fader, P., Iyengar, R., et al. (2005). Choice models and customer relationship management. Marketing Letters, 16(3-4), 279-291. doi:10.1007/s11002005-5892-2.

Kumar, V., \& Petersen, J. A. (2005). Using a customer-level marketing strategy to enhance firm performance: a review of theoretical and empirical evidence. Journal of the Academy of Marketing Science, 33(4), 504-519. doi:10.1177/0092070305275857.

McDowell, M. (1996). An ice cream war: bundling, tying, and foreclosure. European Journal of Law and Economics, 3(3), 197-220. doi:10.1007/BF00709140.

Naik, P. A., \& Raman, K. (2003). Understanding the impact of synergy in multimedia communications. JMR, Journal of Marketing Research, 40, 375-388. November. doi:10.1509/jmkr.40.4.375.19385.

Nickell, S. (1981). Biases in dynamic models with fixed effects. Econometrica, 49(6), 1417-1426. doi: $10.2307 / 1911408$.

Reinartz, W. J., \& Kumar, V. (2000). On the profitability of long-life customers in a noncontractual setting: an empirical investigation and implications for marketing. Journal of Marketing, 64, 17-35. October. doi:10.1509/jmkg.64.4.17.18077.

Reinartz, W. J., \& Kumar, V. (2003). The impact of customer relationship characteristics on profitable lifetime duration. Journal of Marketing, 67, 77-99. January. doi:10.1509/jmkg.67.1.77.18589.

Reinartz, W. J., Thomas, J. S., \& Kumar, V. (2005). Balancing acquisition and retention resources to maximize customer profitability. Journal of Marketing, 69, 63-79. January. doi:10.1509/ jmkg.69.1.63.55511.

Rokkan, A. I., Heide, J. B., \& Wathne, K. H. (2003). Specific investments in marketing relationships: expropriation and bonding effects. JMR, Journal of Marketing Research, 40(2), 210-224. doi:10.1509/jmkr.40.2.210.19223.

Rust, R. T., Ambler, T., Carpenter, G. S., Kumar, V., \& Srivastava, R. K. (2004a). Measuring marketing productivity: current knowledge and future directions. Journal of Marketing, 68(4), 76-89. doi:10.1509/jmkg.68.4.76.42721.

Rust, R. T., Lemon, K. N., \& Zeithaml, V. A. (2004b). Return on marketing: using customer equity to focus marketing strategy. Journal of Marketing, 68(1), 109-127. doi:10.1509/jmkg.68.1.109.24030.

Sargan, J. D. (1958). The estimation of economic relationships using instrumental variables. Econometrica, 26(3), 393-415. doi:10.2307/1907619.

Singer, J. D., \& Willett, J. B. (1991). Modeling the days of our lives: using survival analysis when designing and analyzing longitudinal studies of duration and the timing of events. Psychological Bulletin, 110(2), 268-290. doi:10.1037/0033-2909.110.2.268.

Srivastava, R. K., Shervani, T. A., \& Fahey, L. (1998). Market-based assets and shareholder value: a framework for analysis. Journal of Marketing, 62(1), 2-18. doi:10.2307/1251799.

Thomas, J. S., Blattberg, R. C., \& Kumar, V. (2004). Getting the most out of all your customers. Harvard Business Review, 82(7-8), 116-123.

Venkatesan, R., \& Kumar, V. (2004). A customer lifetime value framework for customer selection and resource allocation strategy. Journal of Marketing, 68, 106-125. October. doi:10.1509/ jmkg.68.4.106.42728.

Webster, F. E. (1992). The changing role of marketing in the corporation. Journal of Marketing, 56(4), 117. doi: $10.2307 / 1251983$. 